\title{
Microstructural Analysis of Examined 33NiCrMoV15 Steel and Investigation of Its Nanomechanical Properties after Machining
}

\author{
Jozef Majerík ${ }^{1}$, Igor Barényi ${ }^{1}$, Josef Sedlák ${ }^{2}$, Roman Kusenda ${ }^{1}$, Maroš Eckert ${ }^{1}$ \\ ${ }^{1}$ Faculty of special technology, Alexander Dubcek University of Trencin. Pri Parku 19, 91106 Trenčín. Slovak \\ Republic. E-mail: jozef.majerik@tnuni.sk, igor.barenyi@tnuni.sk, roman.kusenda@tnuni.sk, maros.ec- \\ kert@tnuni.sk \\ ${ }^{2}$ Institute of manufacturing technology, Faculty of mechanical engineering, Brno University of Technology. Tech- \\ nická 2896/2, 61669 Brno. Czech Republic. E-mail: sedlak@fme.vutbr.cz
}

The authors presented paper deals with experimental measurement and evaluation of nanomechanical properties of hard turned and grinded surfaces on the cross section specimens made of the 33NiCrMoV15 steel in order to perform all investigations. Even before the start of the experiments that investigated the effect of hard finish turning against grinding, it was necessary to subject the investigated 33NiCrMoV15 steel to basic research with regard to its chemical composition, fundamental microstructure and basic mechanical properties. The microstructure was performed on Neophot 32 optical microscope. Chemical composition was realized on the spectral analyzer Spectrolab Jr CCD. Mechanical properties, like nanohardness $H$ and reduced Young modulus $E_{r}$ were subsequently performed on the Hysitron TI950 Triboindenter with a Cube Corner measuring tip, and evaluated by software Triboscan. Based on the acquired values, final 2D nanostructure of $\boldsymbol{H}$ and $\boldsymbol{E}_{r}$ were then evaluated in Matlab. This scientific research, together with all measured and calculated values, is the fundamental that will help to optimizing the quality and used all these results to optimize presented material and technological processes in term of surface integrity.

Keywords: quasistatic nanoindentation, nanohardness, hard finish turning, grinding, microstructural analysis

\section{Introduction}

In the current engineering production process, it is possible to observe the efforts to continuously increase the efficiency of total production as well as to increase the quality of machine components. Thanks to the use of new and innovative types of CNC machine tools and cutting tools with progressive multilayer coatings, this is now possible. This is why it is possible to use increasingly higher cutting parameter values. This also results in an increase in the quality of the machining process, as well as a high dimensional accuracy and productivity of the production process.

The constant trend of increasing the quality of the machining process also forces us to ask an important question whether the use of increasingly high cutting conditions has no significant impact on the properties of the machined surface. The achieved results of realized measurements and research of many domestic and foreign authors and together with practical knowledge point to their significant influence. It is therefore very important today to focus not only on the microgeometry of the machined surfaces, but also on the monitoring of changes in structure and properties within the workpiece surface layer. All these changes are due to deformation and temperature processes in the machining process and have a significant impact on the functional operation of the machine parts.

The practice itself has only confirmed that the onset of damage to many machine parts during their service life occurs mostly on their functional surface or just below it. These acquired knowledge then confirms the need to carry out research into the state of such a surface layer $[2,5,6]$. Realized research and development in the field, published in the articles of the authors $[1,8,9]$, shows the need to evaluate the state of the machined surface in these parts as the result of the finishing process, which is directly dependent on the specific functional conditions of such a surface in industrial operation. This view of the overall evaluation of the machined surface is now called surface integrity. Therefore, according to the authors $[10,11]$ the integrity of the surface can be defined as an overall summary of the conditions under which the functional surface of the component is created taking into account all the effects of the individual technological methods used on the final quality of the machined surface. Therefore, the overall quality of the machined surfaces can generally be assessed according to their achieved dimensional and shape accuracy, surface texture and mechanical properties of the surface layer. $[12,13]$ Therefore, according to the authors, $[1,3]$, among the most frequently evaluated parameters of 
surface integrity, is the microgeometry of the machined surface, the strengthening of the surface layer after finishing, as well as the achieved structural changes in the surface layer.

When starting the study of the already mentioned properties of machined surfaces, it is therefore also necessary to start with the finishing technology itself. This gives us the need to point out the emergence of a new machined surface because each used finishing technology has a significant impact on the final state of the machined surface of the parts. Each thus applied finishing technology on the machined surface leaves special characteristics and thus forms a special condition of such machined surface. Just by the force effect of the cutting tool used, not only the workpiece material leaving in the form of a chip is deformed in its own way in the finishing process, but also a thin surface layer is produced, which thus forms just below the machined surface. For the same reason, the cutting parameters used affect the quality of the machined surface. The cutting speed $[14,15]$ has the greatest influence on all the parameters used. Therefore, the authors chose the cutting speed $v_{c}\left[\mathrm{~m}_{\mathrm{min}} \mathrm{m}^{-1}\right]$ as the variable, and the feed rate $f\left[\mathrm{~mm}^{\mathrm{r}} \mathrm{rev}^{-1}\right]$ as well as the cutting depth $a_{p}[\mathrm{~mm}]$ were determined as constant cutting parameters.

\section{Materials and methods}

In the experimental measurement process, the $33 \mathrm{NiCrMoV} 15$ steel was selected as the workpiece material. In terms of its mechanical properties, it is a medium alloyed $\mathrm{CrNiMoV}$ steel with high strength and at the same time optimal plastic properties. This steel has practical application especially for the production of major large-caliber weapons. Typical examples are weapon systems such as howitzers and tank guns. The steel also has equivalents, especially in terms of its chemical composition. An example of such an equivalent is steel type $35 \mathrm{NiCrMoV} 12-5$, or, according to an amrican standard, is called AISI 4340.

The chemical composition of examined steel $33 \mathrm{NiCrMoV} 15$, which was measured by spectral analysis of the workpiece material, is shown in Table 1 and experimental material using standard methods are shown in Table 2.

Tab. 1 Chemical composition of examined 33NiCrMoV15 steel

\begin{tabular}{|c|c|c|c|c|c|c|c|c|c|}
\hline Element & $\mathrm{C}$ & $\mathrm{Mn}$ & $\mathrm{Si}$ & $\mathrm{Cr}$ & $\mathrm{Ni}$ & $\mathrm{Mo}$ & $\mathrm{V}$ & $\mathrm{P}$ & $\mathrm{S}$ \\
\hline wt..\% & 0.40 & 0.30 & 0.32 & 1.19 & 3.28 & 0.52 & 0.14 & 0.01 & 0.01 \\
\hline
\end{tabular}

Tab. 2 Fundamental mechanical properties of examined $33 \mathrm{NiCrMoV} 15$ steel

\begin{tabular}{|c|c|c|}
\hline Characteristics & Value & Note \\
\hline Tensile strength $\mathrm{R}_{m}[\mathrm{MPa}]$ & 1500 & \\
\hline Proportional limit $\mathrm{Re}[\mathrm{MPa}]$ & 1079 & \\
\hline Hardness $[\mathrm{HV}]$ & 500 & \\
\hline Elongation $A[\%]$ & 20 & \\
\hline \multirow{2}{*}{ Toughness $\mathrm{KCU}\left[\mathrm{J} \cdot \mathrm{cm}^{-2}\right]$} & $20-25$ & at $20^{\circ} \mathrm{C}$ \\
\cline { 2 - 3 } & 20 & at $-50^{\circ} \mathrm{C}$ \\
\hline
\end{tabular}

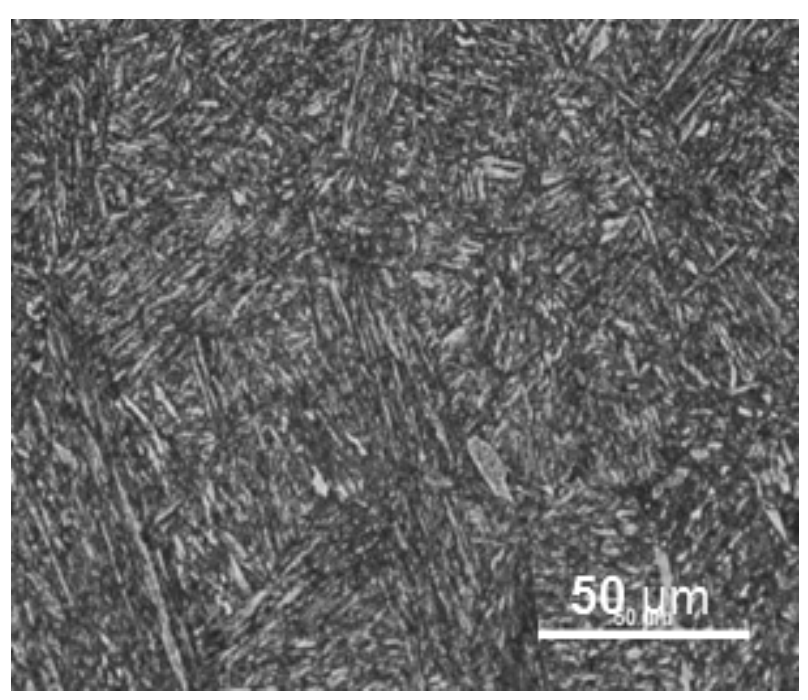

Fig. 1 Micropstructure of base material of steel 33NiCrMoV15 (1000x) etch. Nital
Analysis of the microstructure of the base material as well as of the surface layers after finishing by hard turning and grinding in the investigated $33 \mathrm{NiCr}-$ MoV15 steel was evaluated by the Neophot 32 light optical microscope in the experimental process. The microstructure of the base material according to Fig. 1 is slightly heterogeneous, relatively coarse, and consists of high-release martensite and bainite and fine globular secondary carbides. The average size of the original austenitic grain is about $50 \mu \mathrm{m}$, as can also be seen in Fig. 1. The evaluated microstructure of the base material corresponds to the post-quenching and high temperature tempering of the thick-walled $\mathrm{Cr}$ Ni-Mo-V steels.

A quasi-static nanoindentation analysis $[4,7]$ was performed on a Hysitron Triboindenter TI 950 and its Triboscan evaluation software (can be seen in Figure 4). The quasi-static nanoindentation method was used at selected sites of the microstructure base material of the test specimens (can be seen in Fig. 1) as well as at the surface layers after turning and grinding (can be seen in Figures 2 and 3). The individual research areas were determined with the aid of an optical microscope as a built-in component of the device. Subsequently, the so-called SPM scan of the selected area of $25 \times 25$ $\mu \mathrm{m}$ was realized (can be seen in Fig. 5). The selection of individual sites for realization of the baseline indent alone was defined as a matrix with a number of indents 
on each $5 \times 5$ puncture side. For the indentation of the surface layers after finishing machining, the puncture sites were defined in the vertical direction, i.e. from the surface to the uninfluenced base material (can be seen in Fig. 6). As a loading curve, a standard trapezoid with a maximum of $5000 \mu \mathrm{N}$ and a total indentation time of $t=4 \mathrm{~s}$ was used in the experiment. Figures 5 and 6 illustrate the positions for each base material and surface layer indent. In this manner, the nanoindentation hardness values $H_{r}[\mathrm{GPa}]$ and the reduced $E_{r}$ [GPa] modulus of elasticity in their respective positions were subsequently evaluated using Scilab software. The resulting $H_{r}$ and $E_{r}$ values for the matrix puncture for the base material are through the socalled. 2D maps made in both Matlab and graphically depicted in Fig. 8 and Fig. 9. The resulting 3D topography (Fig. 7) of the investigated region was obtained and evaluated by AFM microscopy on an Oxford Instruments MFP-3D Infinity using AM-FM Viscoelastic Mapping mode.

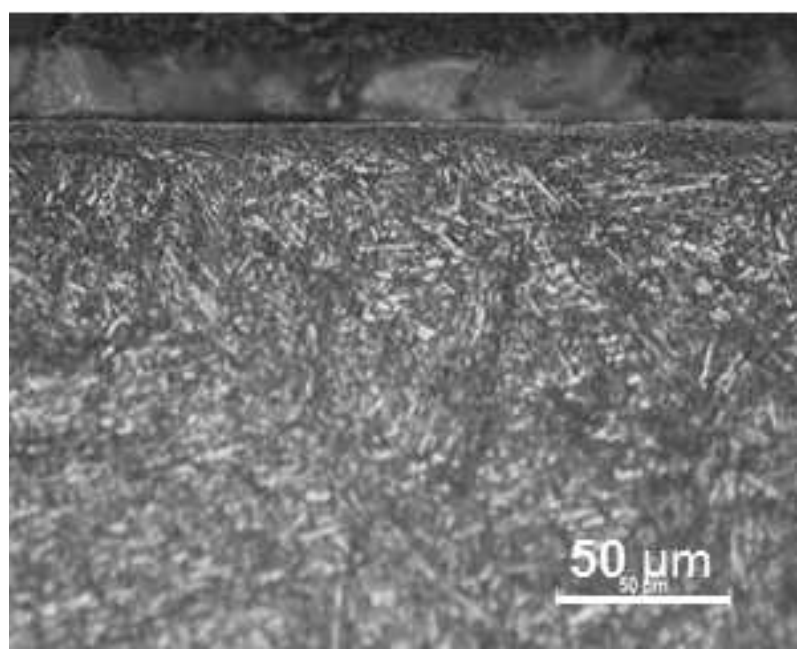

Fig. 2 Surface layer microstructure after bard finish turning in 33NiCrMoV15 steel (1000x), etch. Nital

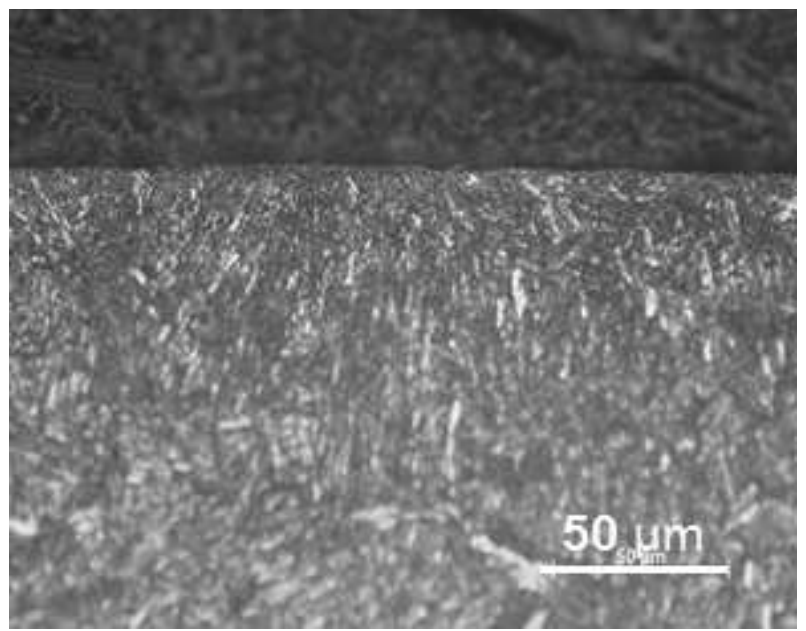

Fig. 3 Surface layer microstructure after grinding in $33 \mathrm{NiCr}$ MoV15 steel (1000x), etch. Nital

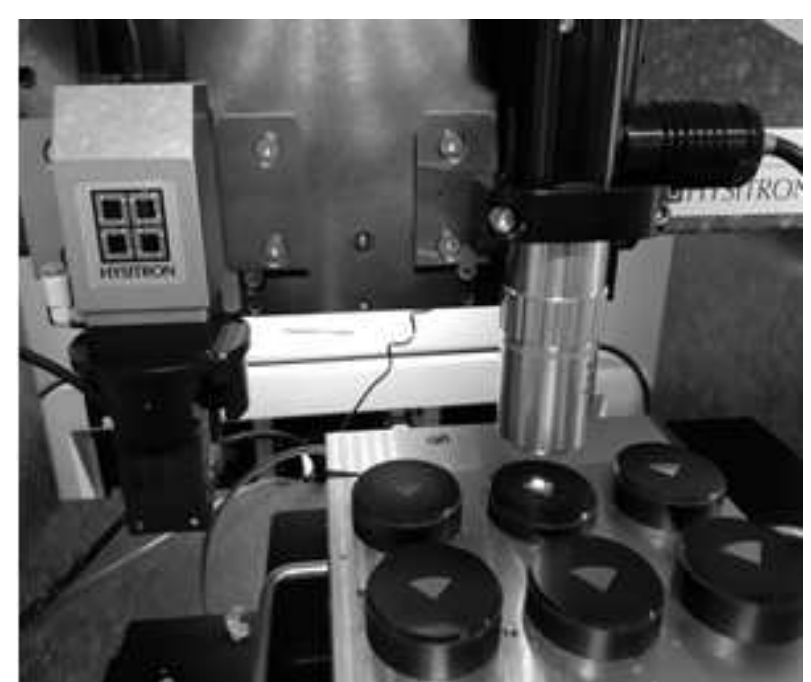

Fig. 4 Configuration of test specimens and method of targeting the investigated area using optics

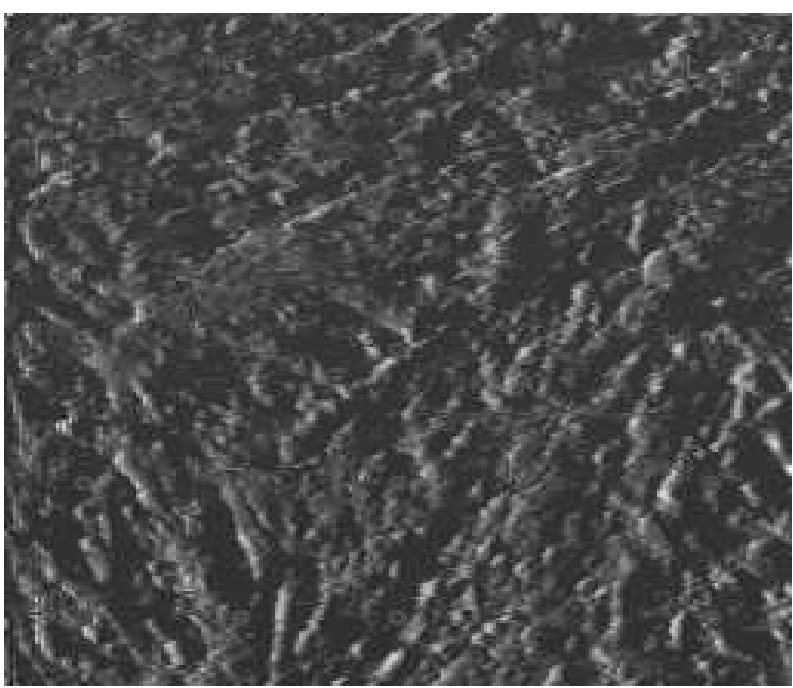

Fig. 5 A method of locating a matrix of individual indents on the SPM scan of the base material being evaluated

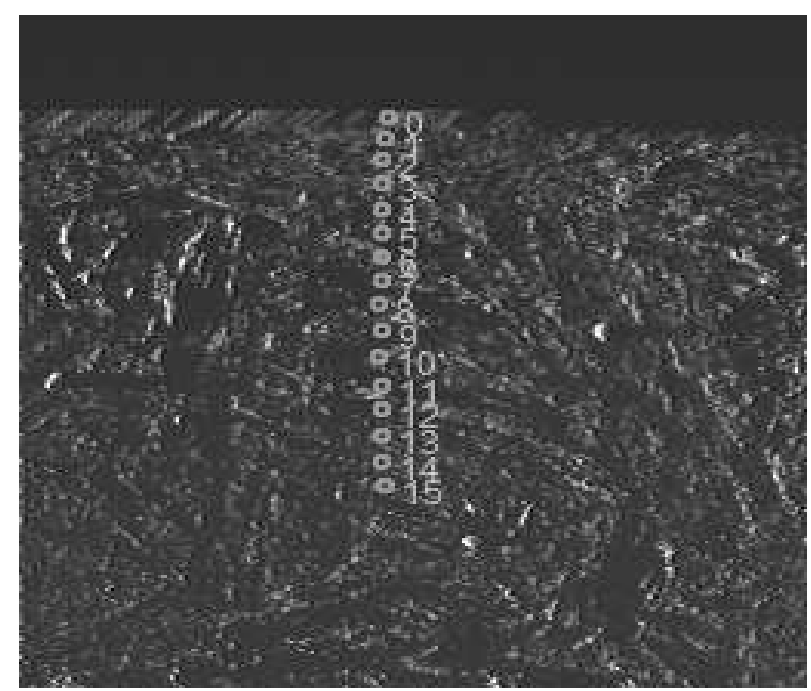

Fig. 6 A method for positioning individual indents in a surface layer after machining on the SPM scan of the area of interest 


\section{Results and discussion}

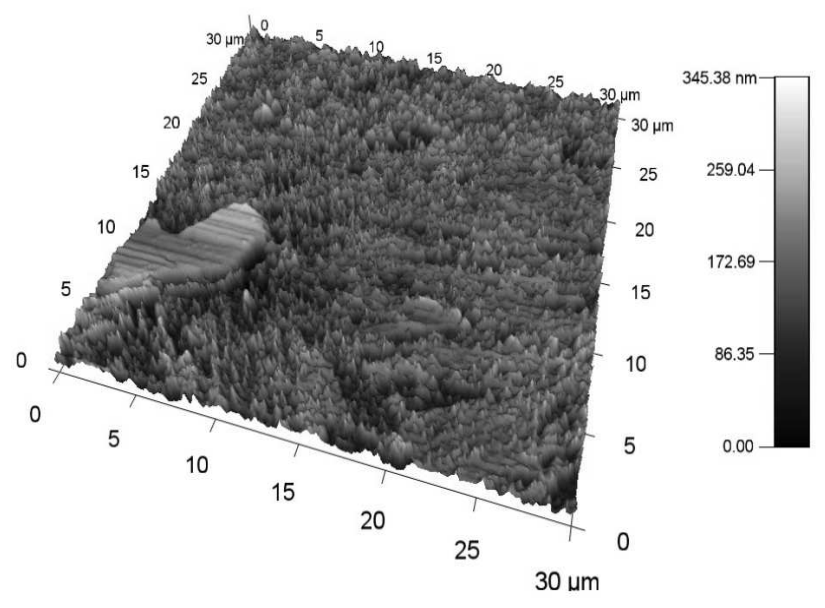

Fig. 7 Display of $3 D$ topography of the examined base material area by AFM microscopy

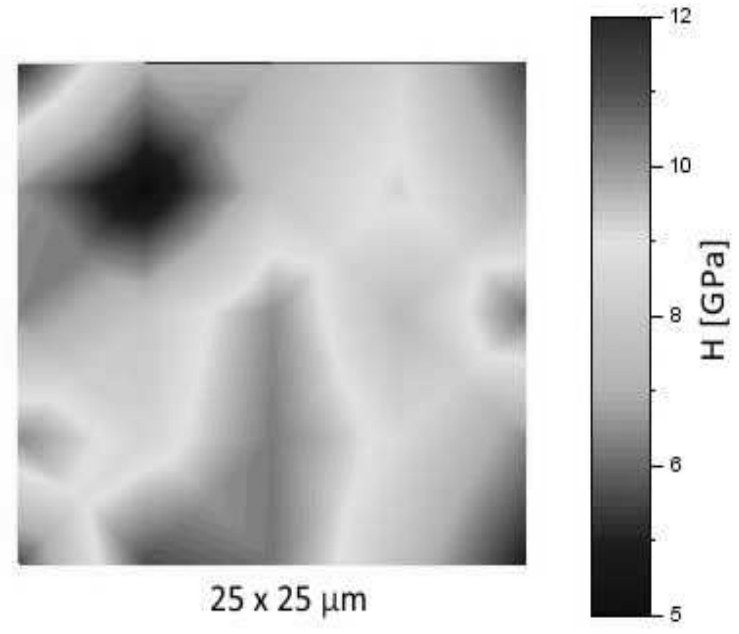

Fig. $\boldsymbol{8}$ An overall view of $2 D$ nano-hardness map $H_{r}$, which is based on measured values

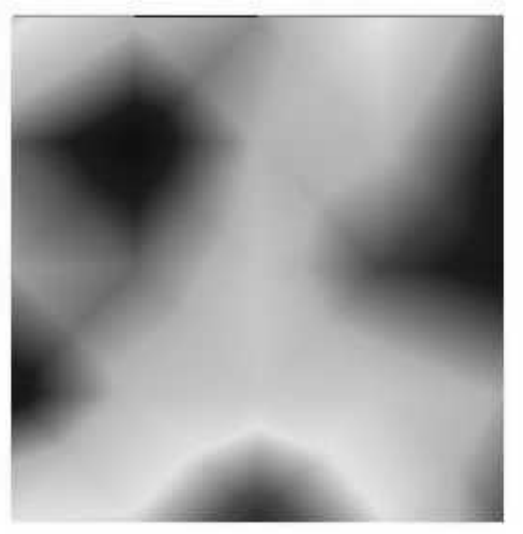

$25 \times 25 \mu \mathrm{m}$

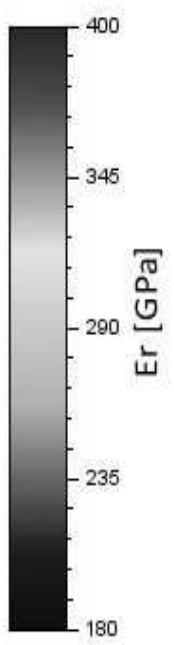

Fig. 9 An overall view of $2 \mathrm{D}$ reduced Youngs modulus map $E_{n}$ which is based on measured values
The microstructural 3D analysis of the base material on a 30x30 $\mu \mathrm{m}$ scanned area, which was performed by AFM microscopic analysis, is shown in Fig. 7 is, as with $2 \mathrm{D}$ optical microscopy, slightly heterogeneous, relatively coarse, and is also formed by highly tempered martensite and bainite with fine globular carbides. The evaluated microstructure therefore corresponds to the state after high temperature tempering of steels with $\mathrm{Cr}-\mathrm{Ni}-\mathrm{Mo}-\mathrm{V}$ thick walls.

Comparison of 2D hardness maps $H_{r}$ and reduced modulus of elasticity $E_{r}$ results in the existence of regions with different hardness and plasticity ratios which correspond to different structural components. For example, areas of very high hardness and high modulus of elasticity correspond to hard and solid particles - carbides, areas of high hardness and higher plastic properties (lower $E_{r}$ ) may correspond to martensitic or bainite phases and regions of low hardness and lower $E_{r}$ residual austenite.

By substantially densifying the puncture matrix, it is possible to map the individual phases present in the microstructure in more detail. However, the large number of indents needed to achieve this goal is time consuming to wear the test tip. Another limiting factor of the density of the indents is that the individual indents must not overlap each other.

The evaluated microstructure analysis of the test bed surface layers after hard turning and grinding, which are formed by plastic deformation after two different finishing operations of the machining, is shown graphically in Fig. 10a, b. The research of the subsurface layers after hard finish turning and grinding showed the effect of plastic deformation in all examined microstructures, which were up to a depth of approximately $5 \mu \mathrm{m}$ in the experiments performed and were microscopically recorded up to a depth of $20 \mu \mathrm{m}$. Subsequently, using the so-called SPM mapping (such as the scanning probe, the Cube Corner indentation tip was used, and the gradient channel was used) of all measured areas $75 \times 75 \mu \mathrm{m}^{2}$ can be seen in Fig. 6. All measuring positions of the indentation tip are then characterized by the indicated points by the order number of the individual indents. Subsequently, the curves obtained were constructed so that the numerically measured nano-hardness values were further processed by non-linear regression using exponential function. The first three grades after the final turning were then characterized by an initial increased surface hardness rate which was partially reduced to a depth of about $15 \mu \mathrm{m}$, followed by a soft nano-hardness degression. The obtained nano-hardness values for the ground surfaces (can be seen in Figure 10b) are characterized by a slight decrease in surface samples compared to the base material, which is due to the high temperatures generated during the grinding process when applying high cutting speed values. Gradually, there is a slight increase in nano-hardness over the 
base material until it is gradually aligned with the unaffected base material of the test specimens.

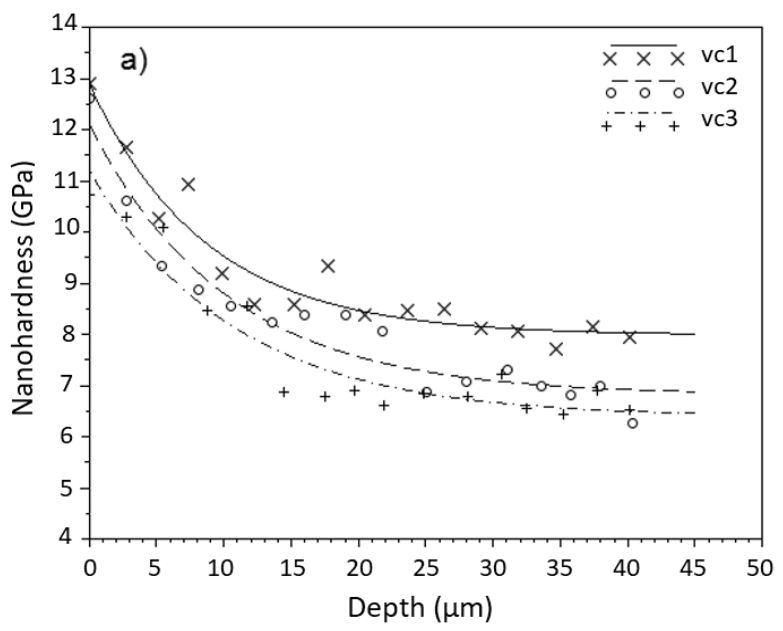

Fig. 10a Measured nano-hardness courses of (a) hard finish turned sutface layers depending on the measured depth

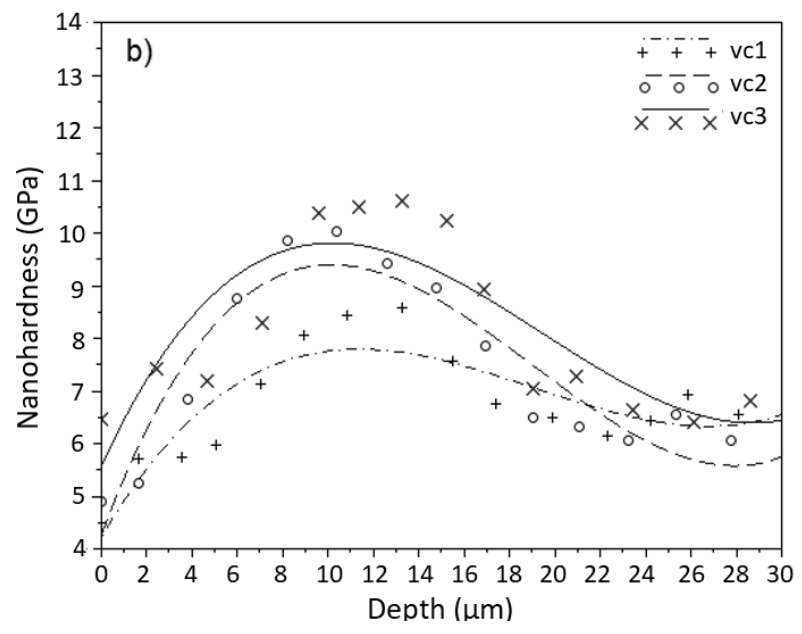

Fig. 10b Measured nano-hardness courses of (b) grinded sutface layers depending on the measured depth

\section{Conclusions}

The above-mentioned research, which analyzed and compared the impact of the hard turning and grinding finishing process to the $33 \mathrm{NiCrMoV} 15$ examined steel. Microstructural analysis was also carried out with using the optical microscope on the base material as well as the obtained surface layers after hard finish turning and grinding. (it can be seen in Figs. 1, 2 and 3). The overall summary of all s obtained and evaluated results can be formulated as follows:

- microstructure of the base workpiece material is slightly heterogeneous, relatively coarse, and consists of highly hardened martensite and bainite, along with fine globular secondary carbides.

- results of the realized metallographic analysis of the perpendicular cross-sections of the test samples after finishing methods showed various changes in the structure of subsurface layers of the metallographic samples after hard finish turning and grinding.

- experimentally obtained values of nano-hardness $H_{r}[\mathrm{GPa}]$ show that the hard-turned surface of the test samples shows an increase of nano-values on the surface and just below it. Then in a continuous way gradually deals with the nano-hardness of the base workpiece material (as can be seen in Fig. 10a). Such a course points to the good adhesion of the surface layer to the base material, which in turn has a beneficial effect on the lifetime of the functional surfaces of components.

- on the contrary, the experimentally obtained nano-hardness values $H_{r}$ [GPa] of grinded test samples according to the graphical dependence obtained directly from Figure $10 \mathrm{~b}$ are marked on their surface by decreasing the nano-hardness values from those measured in depth corresponding to the base material. Such a course is characteristic of grinded surfaces usually with a characteristical network of cracks. On the contrary, this type of course predicts a less rigid connection of the surface layer to the base workpiece material, which in turn reduces the lifetime of the functional surfaces of the thus produced components.

From the general knowledge of technological heredity in the field of strengthening of machined surfaces, the following theses can be formulated. If the cutting conditions change, which results in an increase in the cutting force as well as the degree of plastic deformation, the degree of strengthening then also increases. By extending the time of application of the cutting forces to the machined surface, the depth of the strengthening layers also increases. In carrying out further tests evaluated by the surface integrity parameters of the samples, it may also be desirable to focus, for example, on the wear of the functional surfaces of the cutting tools or, for example, on the residual stresses below the machined surface, along with the implementation of surface functional tests using the Bruker Tribolab tribological apparatus.

\section{Acknowledgement}

This work was supported by the Slovak Research and Development Agency under the contract No. $A P V V-15-0710$ and by the Brno University of 
Technology, Faculty of Mechanical Engineering, Specific research 2019, with the grant "Research of perspective production technologies ", FSI-S$19-6014$.

\section{References}

[1] BARÉNYI, I., MAJERÍK, J., POKORNÝ, Z., SEDLÁK, J., BEZECNÝ, J., DOBROCKÝ, D., JAROS, A., ECKERT, M., JAMBOR, J., KUSENDA, R. (2019). Material and technological investigation of machined surfaces of the OCHN3MFA steel. In: Kovové Materiály - Metallic Materials, Vol. 57, Issue. 2, pp. 131 - 142. Slovak Academy of Sciences.

[2] BARÉNYI, I., MAJERÍK, J., ECKERT, M. (2018). Nanoindentation study of layers after chemical heat treatment of $27 \mathrm{MnCrV} 4$ steel. In: IOP Conference Series: Materials Sciende and Engineering, Vol. 393, No. 1, pp.1- 7. KOD 2018.

[3] BRAGA, C., DA SILVA, L. R., BARBOSA, E. J. A., CORREA, E. C. S. (2017). Surface integriy characterization of hardened AISI 4340 steel in grinding proces with biodegradable formulation of cutting fluids. In: Materiala Research, Vol. 20, Issue 2, pp. 496-501.

[4] FISHER-CRIPPS, A. C. (2013). Nanoindentation, $3^{\text {rd }}$ Edition, 279 p. Springer Science, New York.

[5] CHEN, T., TAN, L., LU, Z., XU, H. (2017). The effect of grain orientation on nanoindentation behaviour of model austenitic alloy $\mathrm{Fe}$ 20Cr-25Ni. In: Acta Materialia, Vol. 138, pp. 83 -91 .

[6] IRACHETA, O., BENNETT, C. J., SUN, W. (2017). The influence of the indentation size and relation to the size of the microstructure of three polycrystalline materials indented with a Berkovich indenter. In: Materials Science \& Engineering, Vol. 706, pp. 330 - 341.

[7] OLIVER, W., PHARR, G. M. (1992). An improved Technique for determining Hardness and Elastic Modulus using Load Displacement Sensing Indentation Experiments. In: Journal of Material Research, Vol. 7, No. 6, pp. 1564 - 1583.
[8] POKORNÝ, Z., HRUBÝ, V., STUDENÝ, Z. (2016). Effect of Nitrogen on Surface Morphology of Layers. In: NOVY, L. (1996). Effect of Nitrogen on Surface Morhoplogy of Layers. In: Kovové Materiály - Metallic Materials, Vol. 54, Issue. 2, pp. 119 - 124. Slovak Academy of Sciences.

[9] RANJAN DAS, S., PANDA, A., DHUPAL, D. (2018). Hard turning of AISI 4340 steel using coated carbide insert: surface roughness, tool wear, chip morphology and cost estimation. In: Materials Today proceedings, Vol. 5, Issue 2, pp. 6560-6569.

[10] SEDLÁK, J., JAROŠ, A., SLANÝ, M., KOUŘIL, K., MAJERÍK, J., BARÉNYI, I. (2018). Analysis of the power load when finishing very precise holes by reaming head MT3. In: Manufacturing Technology, Vol. 18, No. 4, pp. 659-666.

[11] SEDLÁK, J., TROOP, J., CHLADIL, J., POLZER, A., OSIČKA, K. (2016). Analysis of selected aspects of turned bearing rings regarding required workpiece quality. In: Manufacturing technology, Vol. 16, Issue 3, pp. 612-622.

[12] DAVIM, J. P. (2010). Surface integrity in machining, $1^{\text {st }}$ Edition, 213 p. Springer Verlag London Limited.

[13] DAS, A., PATEL, S. K, SATEESH KUMAR, C., BISWAL, B. B. (2018). Experimental investigation of various surface integrity aspects in hard turning of AISI 4340 alloy steel with coated and uncoated cermet. In: IOP Conference Series: Materials Sciences and Engineering, Vol. 338, No. 1, Article Number 012056, $7^{\text {th }}$ National Conference on Processing and Characterization of Materials, NCPCM 2017.

[14] MADL, J., RAZEK, V., KOUTNY, V., KAFKA, J. (2013). Surface integrity in notches machining. In: Manufacturing technology, Vol. 13, Issue 2, pp. 188-193.

[15] KUNDRÁK, J. (2011). Alternative machining procedures of hardened steels. In: Manufacturing technology, Vol. 11, pp. 32-39. 